\title{
Therapeutic Outcomes and Risk Factors for Complications of Endoscopic Papillectomy: A Retrospective Analysis of a Single-Center Study
}

\author{
Lei Jiang $\mathbb{D}^{1,2, *}$ \\ Ningli Chai ${ }^{1,2, *}$ \\ Mingyan $\mathrm{Li}^{2}$ \\ Enqiang Linghu ${ }^{1,2}$
}

'School of Medicine, Nankai University, Tianjin, 30007I, People's Republic of China; ${ }^{2}$ Department of Gastroenterology and Hepatology, First Medical Center of Chinese PLA General Hospital and Chinese PLA Medical College, Beijing, 100853, People's Republic of China

*These authors contributed equally to this work
Correspondence: Enqiang Linghu Department of Gastroenterology and Hepatology, First Medical Center of Chinese PLA General Hospital and Chinese PLA Medical College, No. 28 Fuxing Road, Haidian District, Beijing, 100853, People's Republic of China Tel +86 106818 2255- 499292(o) Fax +86 $1068154653 ;+861055499292$ Email linghuenqiang@vip.sina.com
Purpose: Endoscopic papillectomy (EP) has been accepted as a viable alternative therapy to surgery in benign duodenal papillary lesions. However, postoperative complications limit its widespread clinical application. This study aimed to evaluate the overall safety of the EP procedure and identify significant risk factors of post-EP complications.

Patients and Methods: We retrospectively collected 76 patients who had undergone EP in Chinese PLA General Hospital from 2016 to 2019 and graded their postoperative complications. We assessed twelve patient-, disease- or procedure-related variables to identify risk factors related to the occurrence of post-EP complications using both univariate and multivariate analyses.

Results: Among the 76 patients included in this study, the incidence of entire post-EP complications was $36.8 \%$, most of which were in a mild form. In both univariate and multivariate analyses, the pathologic tumor types, especially high-grade intraepithelial neoplasia (HIN), and the placement of stents were significantly associated with the occurrence of post-EP complications. Patients with HIN tumors were more likely to have post-EP pancreatitis, bleeding, and overall complications (odds ratio (OR) 11.66, 95\% confidence interval (CI) 2.91-62.5, $P=0.001$; OR 6.52, 95\% CI 1.45-46.77, $P=0.027$; OR 9.81, 95\% CI 2.75-44.04, $P=0.001$, respectively). Pancreatic stent placement may contribute to the occurrence of post-EP pancreatitis (OR 7.61, 95\% CI 1.37-64.53, $P=0.033$ ). While biliary stent placement was found negatively related to the occurrence of post-EP bleeding and overall complications (OR 0.02, 95\% CI $0-0.37, P=0.016$; OR $0.11,95 \%$ CI $0.01-0.99, P=$ 0.05 , respectively).

Conclusion: EP is a safe procedure for papillary lesion treatment with a low rate and generally mild postoperative complications. Two factors are significantly associated with the occurrence of complications. The selection of eligible patients and suitable procedures is important to reduce the complication rate and severity.

Keywords: duodenal papillary lesion, endoscopic papillectomy, complications, risk factors

\section{Introduction}

Duodenal papillary adenoma (PA) is a type of rare benign tumor with an incidence range from $0.04 \%$ to $0.12 \%$ that can potentially become malignant and develop into cancer. Complete resection of PA therefore is a commonly recommended treatment. ${ }^{1-3}$ Currently, endoscopic papillectomy (EP) has been widely applied in the resection of PA as well as other papillary lesions and recognized as a less traumatic alternative to surgery. ${ }^{4-7}$ Despite it is relatively easier to operate and less traumatic compared with 
surgery, EP is found to be associated with a high rate of postoperative complications $(8-35 \%) .^{6-14}$

The common post-EP complications include pancreatitis, bleeding, perforation, cholangitis, and multiple organ dysfunction syndrome (MODS). Most post-EP complications are mild or moderate; however, severe complications can be rather intractable and lead to poor prognosis or even death in the worst-case situation. ${ }^{12-15}$ EP has been thus considered as a relatively high-risk endoscopic procedure, which limits its clinical application.

Identification of risk factors is critical for post-EP complication prevention and postoperative recovery. Multiple factors, including patient-, procedure- or even endoscopistrelated factors, have been proposed to contribute to the development of post-EP complications. ${ }^{7,16-22}$ Nevertheless, large-scale studies evaluating the safety and complications related to EP are rarely reported, and many previous studies have produced conflicting results. $9,10,19,21,23,24$ The aim of this study was to assess the safety of EP and identify the risk factors of post-EP complications using univariate and multivariate analyses in a high-volume single-center, retrospective study in China.

\section{Patients and Methods Study Population}

We conducted a retrospective observational study of clinical cases treated with EP from 2016 to 2019 in the Digestive Endoscopy Unit of the Department of Gastroenterology at Chinese PLA General Hospital. A total of 76 patients treated with EP were enrolled in this study. The criteria for enrolled patients included: (1) papillary lesions successfully resected by EP; (2) lesion diameter $\leq 5 \mathrm{~cm}$; (3) cases with integrated information. Patients with malignant tumors or without integrated information were excluded from the analysis.

This study was conducted in accordance with the Declaration of Helsinki. The requirement for ethical approval was waived according to the Ethics Committee of Chinese PLA General Hospital due to the retrospective nature of the study. Written informed consent was obtained from each participant of this study.

\section{Endoscopic Papillectomy Procedure}

All of the EP procedures were performed successfully by experienced endoscopists with over 10 years of experience in endoscopic retrograde cholangiopancreatography (ERCP). An example of the EP procedure is shown in
Figure 1. Detailed EP procedure and post-EP follow-up are described in the supplementary material.

\section{Data Collection}

The patients' medical records were reviewed for data on age, sex, chief complaint, tumor size, tumor pathologic type, etc. The nature of EP-related interventions was collected, including submucosal injection (yes or no), resection (en bloc or piecemeal), stent placement (yes or no), pancreatography (yes or no), endoscopic sphincterotomy (EST, yes or no), and hemostasis, etc. Besides postoperative symptoms, complications, and relevant treatment, outcomes were also retrieved.

\section{Complication Definition and Grade}

Post-EP pancreatitis was defined as an over three-fold increase in serum amylase with abdominal pain. Post-EP bleeding was defined as a progressive drop in hemoglobin after the procedure or active bleeding found in postoperative or follow-up endoscopy. Post-EP perforation was defined as a slight leak or definite perforation found by follow-up endoscopy, abdominal CT, or ultrasound. In the present study, post-EP complications were graded based on the consensus criteria established by Cotton et al. ${ }^{25}$

\section{Statistical Analysis}

Statistical analyses were performed using SPSS statistics 19.0 (IBM, Armonk, NY, USA) and Prism 8 (GraphPad, San Diego, CA, USA). The enumeration data are expressed in percentage, and the measurement data are expressed as mean $( \pm \mathrm{SD})$. To analyze the risk factors of complications, the enumerated data were compared using the chi-squared test or Fisher's exact test, and the measurement data were compared with the Student's $t$-test or Welch's $t$-test. Variables with a $P$-value $<0.1$ in the univariate analysis were all included in a forward stepwise multiple logistic regression model to perform multivariate analysis and identify the independent risk factors for post-EP complications. A $P$-value less than 0.05 was considered statistically significant.

\section{Results \\ EP Cases and Procedures}

A total of 76 patients who underwent EP were included in the study with their characteristics summarized in Table 1. The patients' mean age was $58.4 \pm 12.1$ years (mean $\pm \mathrm{SD}$ ), $47.5 \%$ were female, and $39.5 \%$ were asymptomatic before the operation. Among the symptomatic patients, the most 


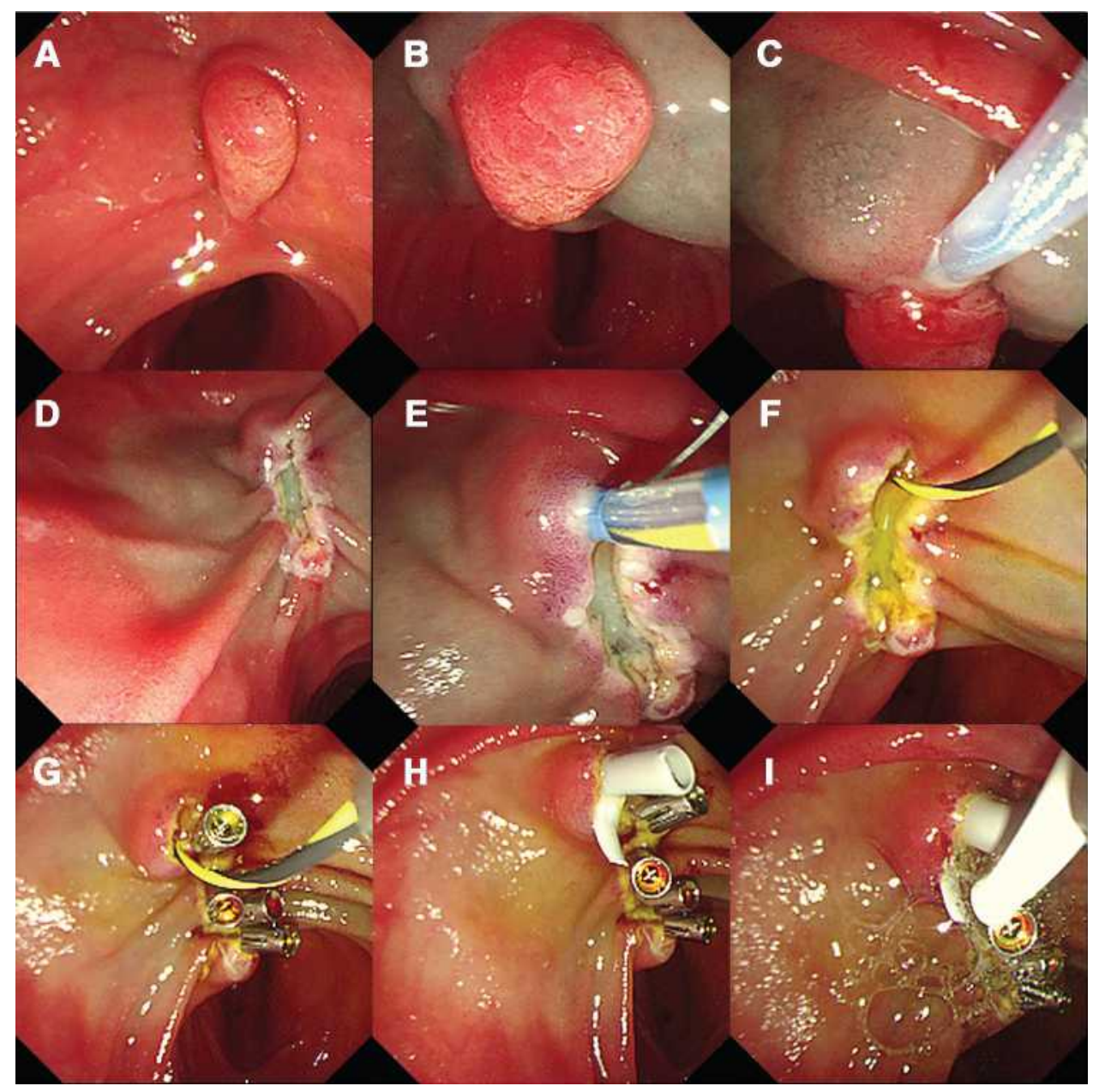

Figure I An example of EP procedure. (A) Observe the papillary lesion; (B) Lift the lesion by submucosal injection (when necessary); (C and D) En bloc resection of the lesion with endoloop; (E and F) Cannulate the bile duct, and retain the guidewire in the bile duct; (G) Hemostasis with metal clips; (H) Implant the biliary stent; (I) Spray hemostatic sealant (fibrin glue) on the closed wound.

common chief complaint was abdominal pain or distension (32.9\%), followed by jaundice (10.5\%), cholangitis (17.9\%), pancreatitis $(6.6 \%)$, and fever and fatigue $(2.6 \%)$.

EP was performed successfully by experienced endoscopists in all the patients. Submucosal epinephrine saline injection was applied in $17.1 \%$ of the patients (Table 1). Lesions were wholly removed either by en bloc resection (80.3\% of the patients) or piecemeal (19.7\%). Single or multiple hemostatic approaches were applied to prevent or manage bleeding, including metal clips (82.9\%), hemostatic sealant $(29 \%)$, and epinephrine solution injection $(22.4 \%)$. In $89.5 \%$ of the patients, plastic stents were placed in either pancreatic duct or bile duct, or both (39.5\%, 30.3\%, and $19.7 \%$, respectively). Only eight patients were treated without any stent placement.

Disease-related characteristics were recorded during and after the EP procedure (Table 1). The mean size of the lesion was $4.48 \pm 5.74 \mathrm{~cm}^{2}$. Pathologic findings of the resection specimens included adenoma without intraepithelial neoplasia (Non-IN, 46.1\%), low-grade intraepithelial neoplasia (LIN, 14.5\%), high-grade intraepithelial neoplasia (HIN, $36.8 \%$ ), and neuroendocrine tumor (NT, 2.63\%). Pancreatography was performed in $51.3 \%$ of the patients. EST was performed in $31.6 \%$ of the patients. Bile duct dilatation and pancreatic duct dilatation were observed in $37.5 \%$ and $18 \%$ of the patients, respectively.

\section{Incidence of Post-EP Complications}

Five different types of complications were observed in 28 of 76 patients (36.8\%), including pancreatitis, bleeding, MODS, perforation, and cholangitis. Fourteen patients showed more than one complication. Pancreatitis was the most frequent complication occurring in 19 cases (25\%), followed by bleeding in 14 cases (18.4\%), MODS in six 
Table I Characteristics of Patients in the Overall Study Population

\begin{tabular}{|c|c|}
\hline \multicolumn{2}{|l|}{ Characteristics of Patients } \\
\hline Age (mean $\pm S D$, range, years) & $58.4 \pm 12.1(26-88)$ \\
\hline Sex (Female n, \%) & $36(47.5)$ \\
\hline \multicolumn{2}{|l|}{ Chief complaint (n, \%) } \\
\hline Abdominal pain or distension & $25(32.9)$ \\
\hline Jaundice & $8(10.5)$ \\
\hline Cholangitis & $6(7.9)$ \\
\hline Pancreatitis & $5(6.6)$ \\
\hline Fever and fatigue & $2(2.6)$ \\
\hline Incidental finding & $30(39.5)$ \\
\hline \multicolumn{2}{|l|}{ Characteristics of disease } \\
\hline Tumor size (mean $\pm \mathrm{SD}$, range, $\mathrm{cm}^{2}$ ) & $4.48 \pm 5.74(0.6-28)$ \\
\hline Bile duct dilatation (n/total, \%) & $12 / 32(37.5)$ \\
\hline Pancreatic duct dilatation (n/total, \%) & $7 / 39(18)$ \\
\hline \multicolumn{2}{|l|}{ Pathologic type (n, \%) } \\
\hline Non-IN & $35(46.1)$ \\
\hline LIN & II (I4.5) \\
\hline HIN & $28(36.8)$ \\
\hline NT & $2(2.63)$ \\
\hline \multicolumn{2}{|l|}{ Interventions } \\
\hline Submucosal injection (n, \%) & $13(17.1)$ \\
\hline \multicolumn{2}{|l|}{ Type of resection (n, \%) } \\
\hline En bloc & $61(80.3)$ \\
\hline Piecemeal & $15(19.7)$ \\
\hline \multicolumn{2}{|l|}{ Hemostasis (n, \%) } \\
\hline Metal clips & $63(82.9)$ \\
\hline Hemostatic sealant & $22(29)$ \\
\hline Epinephrine & $17(22.4)$ \\
\hline \multicolumn{2}{|l|}{ Stent implantation ( $\mathrm{n}, \%)$} \\
\hline Pancreatic stent & $30(39.5)$ \\
\hline Biliary stent & $23(30.3)$ \\
\hline Double stent & $15(19.7)$ \\
\hline Non stent & $8(10.5)$ \\
\hline Pancreatography (n, \%) & $39(51.3)$ \\
\hline Endoscopic sphincterotomy (n, \%) & $24(31.6)$ \\
\hline
\end{tabular}

Abbreviations: non-IN, non-intraepithelial neoplasia; HIN, high-grade intraepithelial neoplasia; LIN, low-grade intraepithelial neoplasia; NT, neuroendocrine tumor.

$(7.9 \%)$, perforation in three $(3.9 \%)$, and cholangitis in one case (1.3\%). Complications were classified into three grades: mild, moderate, and severe (Table 2). Pancreatitis was mild in most cases (68.4\%), while bleeding of different grades occurred in more similar incidences $(42.99 \%$,
Table 2 Post-EP Complications in 76 Patients

\begin{tabular}{|l|l|l|l|l|}
\hline \multirow{2}{*}{ Complications } & \multirow{2}{*}{$\begin{array}{l}\text { Total (n, \% of } \\
\text { Total Procedure) }\end{array}$} & \multicolumn{2}{|c|}{ Severity (n, \% of Complications) } \\
\cline { 3 - 5 } & & Mild & Moderate & Severe \\
\cline { 3 - 5 } & $19(25)$ & $13(68.4)$ & $5(26.3)$ & $1(5.3)$ \\
Pancreatitis & $14(18.4)$ & $6(42.9)$ & $3(21.4)$ & $5(35.7)$ \\
Peeding & $3(3.9)$ & $0(0)$ & $1(33.3)$ & $2(66.7)$ \\
Cholangitis & $1(1.3)$ & $0(0)$ & $1(100)$ & $0(0)$ \\
MODS & $5(6.6)$ & $0(0)$ & $0(0)$ & $5(100)$ \\
Overall & $28(36.8)$ & $17(60.7)$ & $6(21.4)$ & $5(17.9)$ \\
complications & & & & \\
\hline
\end{tabular}

Abbreviation: MODS, multiple organ dysfunction syndrome.

$21.4 \%$, and $35.7 \%$, respectively). Considering the nature of perforation and MODS, most of them were classified as moderate or severe (Table 2). The MODS in this study was defined as the development of potentially reversible physiologic derangement involving two or more organ systems after EP procedure, such as pancreatitis, cholangitis, anemia, and low blood pressure, etc. All of the six MODS cases were successfully reversed after timely treatment. All of the complications were successfully managed, and there was no EP-related death in this study.

\section{Univariate Analysis of Risk Factors for Post-EP Complications}

To identify significant individual risk factors, we next performed univariate analysis for the comparison of the patients with $(n=28)$ and without $(n=48)$ post-EP complications. Twelve variables, which were classified as patient-, disease-, and intervention-related variables, were included in the risk factor analysis. Univariate analysis revealed that the pathologic tumor type and biliary stent placement were significantly associated with the occurrence of overall complications. Patients with non-IN adenoma and biliary stent placement were less likely to have post-EP complications, with odds ratios (ORs) of 0.234 (95\% confidence interval [CI], $0.09-0.65 ; P=0.008)$ and 0.25 (95\% CI, 0.09-0.88; $P=0.023)$, respectively. Patients with HIN lesions had a higher possibility to develop post-EP complications with an OR of $6.84(95 \%$ CI, 2.41-20.49; $P=$ $0.0002)$. No statistically significant association was found between the occurrence of complications and other variables, including patients' characteristics (age, sex, etc.), tumor size, bile or pancreatic duct dilatation, submucosal injection, pancreatography, resection, and hemostatic method (Table 3). 
Table 3 Univariate Analysis of Post-EP Complication Related Risk Factors

\begin{tabular}{|c|c|c|c|c|}
\hline Variable & $\begin{array}{l}\mathbf{n} \text { in Complication Cases / } \\
\text { Total } \mathbf{n} \text { of Occurrence }\end{array}$ & OR & $95 \% \mathrm{Cl}$ & $P$ \\
\hline \multicolumn{5}{|l|}{ Characteristics of patients } \\
\hline Age (mean, years) & 58.75 & & $-6.26-5.26$ & 0.863 \\
\hline Sex (Female) & $13 / 36$ & 0.94 & $0.37-2.34$ & $>0.999$ \\
\hline \multicolumn{5}{|l|}{ Indication of EP } \\
\hline Abdominal pain or distension & $9 / 25$ & 0.95 & $0.36-2.57$ & $>0.999$ \\
\hline Jaundice & $3 / 8$ & 1.03 & $0.26-4.48$ & $>0.999$ \\
\hline Cholangitis & $1 / 6$ & 0.32 & $0.03-2.64$ & 0.404 \\
\hline Pancreatitis & $1 / 5$ & $0.4 I$ & $0.03-2.73$ & 0.646 \\
\hline Fever and fatigue & $2 / 2$ & Infinity & $0.8 \mathrm{I}-$ Infinity & 0.133 \\
\hline Incidental finding & $12 / 30$ & 1.25 & $0.47-3.20$ & 0.808 \\
\hline \multicolumn{5}{|l|}{ Characteristics of disease } \\
\hline Tumor size (mean, $\mathrm{cm}^{2}$ ) & 2.313 & & $-0.90-4.64$ & 0.181 \\
\hline Bile duct dilatation & $5 / 12$ & 0.71 & $0.16-2.70$ & 0.726 \\
\hline Pancreatic duct dilatation & $3 / 7$ & 1.14 & $0.39-2.53$ & $>0.999$ \\
\hline \multicolumn{5}{|l|}{ Pathologic type } \\
\hline Non-IN & $7 / 35$ & 0.24 & $0.09-0.65$ & $0.008^{* *}$ \\
\hline LIN & $3 / 11$ & 0.60 & $0.16-2.33$ & 0.737 \\
\hline HIN & $18 / 28$ & 6.84 & $2.4 I-20.49$ & $0.0002 * * *$ \\
\hline NT & $0 / 2$ & 0.00 & $0.00-3.70$ & 0.528 \\
\hline \multicolumn{5}{|l|}{ Interventions } \\
\hline Submucosal injection & $3 / 13$ & 0.46 & $0.13-1.63$ & $0.35 I$ \\
\hline \multicolumn{5}{|l|}{ Type of resection } \\
\hline En bloc & $23 / 6 I$ & 1.21 & $0.36-3.58$ & $>0.999$ \\
\hline Piecemeal & & & & \\
\hline \multicolumn{5}{|l|}{ Hemostasis } \\
\hline Metal clips & $23 / 63$ & 0.90 & $0.27-2.94$ & $>0.999$ \\
\hline Hemostatic sealant & $8 / 22$ & 0.97 & $0.33-2.82$ & $>0.999$ \\
\hline Epinephrine & $7 / 17$ & 1.27 & $0.45-3.79$ & 0.777 \\
\hline \multicolumn{5}{|l|}{ Stent implantation } \\
\hline Pancreatic stent & $15 / 30$ & 2.54 & $0.99-6.98$ & 0.088 \\
\hline Biliary stent & $4 / 23$ & 0.25 & $0.09-0.88$ & $0.0225^{*}$ \\
\hline Double stent & $7 / 15$ & 1.67 & $0.56-4.77$ & 0.388 \\
\hline Non stent & $2 / 8$ & 0.54 & $0.11-2.41$ & 0.703 \\
\hline Pancreatography & $15 / 39$ & 1.15 & $0.47-2.93$ & 0.815 \\
\hline
\end{tabular}

Notes: $* P \leq 0.05, * * P \leq 0.01, * * * P \leq 0.001$.

Abbreviations: non-IN, non-intraepithelial neoplasia; HIN, high-grade intraepithelial neoplasia; LIN, low-grade intraepithelial neoplasia; NT, neuroendocrine tumor; OR, odds ratio; $\mathrm{Cl}$, confidence interval.

Given that pancreatitis and bleeding occurred most frequently, we further evaluated the risk factors specifically for these two complications (Tables 4 and 5). Univariate analysis revealed that tumor pathology, hemostatic intervention, and stent implantation were significantly associated with the occurrence of post-EP pancreatitis. HIN tumors and pancreatic stent implantation were positively related to the occurrence post-EP pancreatitis with ORs of 6.07 (95\% CI, 
Table 4 Univariate Analysis of Post-EP Pancreatitis Related Risk Factors

\begin{tabular}{|c|c|c|c|c|}
\hline Variable & n in Pancreatitis Cases /Total $n$ of Occurrence & OR & $95 \% \mathrm{Cl}$ & $\boldsymbol{P}$ \\
\hline \multicolumn{5}{|l|}{ Characteristics of patients } \\
\hline Age (mean, years) & 54.32 & & $-0.80-11.78$ & 0.086 \\
\hline Sex (Female) & $7 / 36$ & 0.56 & $0.21-1.53$ & 0.427 \\
\hline \multicolumn{5}{|l|}{ Indication of EP } \\
\hline Abdominal pain or distension & $7 / 25$ & 1.26 & $0.46-3.56$ & 0.779 \\
\hline Jaundice & $1 / 8$ & 0.40 & $0.03-2.59$ & 0.671 \\
\hline Cholangitis & $1 / 6$ & 0.58 & $0.05-4.94$ & $>0.999$ \\
\hline Pancreatitis & $1 / 5$ & 0.74 & $0.06-5.04$ & $>0.999$ \\
\hline Fever and fatigue & $0 / 2$ & 0.00 & $0.00-6.53$ & $>0.999$ \\
\hline Incidental finding & $9 / 30$ & 1.54 & $0.54-4.28$ & 0.431 \\
\hline \multicolumn{5}{|l|}{ Characteristics of disease } \\
\hline Tumor size (mean, $\mathrm{cm}^{2}$ ) & 3.84 & & $-3.59-5.20$ & 0.713 \\
\hline Bile duct dilatation & $2 / 12$ & 0.30 & $0.06-1.56$ & 0.248 \\
\hline Pancreatic duct dilatation & $\mathrm{I} / 7$ & 0.43 & $0.03-3.79$ & 0.653 \\
\hline \multicolumn{5}{|l|}{ Pathologic type } \\
\hline Non-IN & $3 / 35$ & 0.15 & $0.04-0.52$ & $0.003^{* *}$ \\
\hline LIN & $3 / 11$ & 1.15 & $0.30-4.71$ & $>0.999$ \\
\hline HIN & $13 / 28$ & 6.07 & $2.06-20.13$ & $0.002 * *$ \\
\hline NT & $0 / 2$ & 0.00 & $0.00-6.53$ & $>0.999$ \\
\hline \multicolumn{5}{|l|}{ Interventions } \\
\hline Submucosal injection & $3 / 13$ & 0.88 & $0.24-3.24$ & $>0.999$ \\
\hline \multicolumn{5}{|l|}{ Type of resection } \\
\hline En bloc & $16 / 6 \mid$ & 1.42 & $0.34-5.19$ & 0.748 \\
\hline Piecemeal & & & & \\
\hline \multicolumn{5}{|l|}{ Hemostasis } \\
\hline Metal clips & $15 / 63$ & 0.70 & $0.21-2.31$ & 0.726 \\
\hline Hemostatic sealant & $7 / 22$ & 1.63 & $0.58-4.79$ & 0.395 \\
\hline Epinephrine & $6 / 17$ & 1.60 & $0.69-3.36$ & 0.342 \\
\hline \multicolumn{5}{|l|}{ Stent implantation } \\
\hline Pancreatic stent & $12 / 30$ & 3.71 & $1.33-10.26$ & $0.028^{*}$ \\
\hline Biliary stent & $4 / 23$ & 0.53 & $0.17-1.73$ & 0.395 \\
\hline Double stent & $3 / 15$ & 0.70 & $0.19-2.91$ & 0.748 \\
\hline Non stent & $0 / 8$ & 0.00 & $0.00-1.37$ & 0.189 \\
\hline Pancreatography & $10 / 39$ & 1.07 & $0.39-3.03$ & $>0.999$ \\
\hline
\end{tabular}

Notes: $* P \leq 0.05, * * P \leq 0.01$.

Abbreviations: non-IN, non-intraepithelial neoplasia; HIN, high-grade intraepithelial neoplasia; LIN, low-grade intraepithelial neoplasia; NT, neuroendocrine tumor; OR, odds ratio; $\mathrm{Cl}$, confidence interval.

$2.06-21.13 ; P=0.002)$ and $3.71(95 \% \mathrm{CI}, 1.33-10.26 ; P=$ $0.028)$, respectively. Tumor with no intraepithelial neoplasia was inversely proportional to the risk of developing post-EP pancreatitis with an OR of $0.15(95 \% \mathrm{CI}, 0.04-0.52 ; P=$ 0.003 ) (Table 4). On the other hand, pathologic types of tumors, hemostatic sealant application, and biliary stent implantation were significantly associated with the occurrence of post-EP bleeding. Patients who received a biliary stent and/or hemostatic sealant were less likely to have postEP bleeding with ORs of $0(95 \% \mathrm{CI}, 0-0.43 ; P=0.007)$ and 
Table 5 Univariate Analysis of Post-EP Bleeding Related Risk Factors

\begin{tabular}{|c|c|c|c|c|}
\hline Variable & $\begin{array}{l}\mathbf{n} \text { in Bleeding Cases / } \\
\text { Total } \mathbf{n} \text { of Occurrence }\end{array}$ & OR & $95 \% \mathrm{Cl}$ & $P$ \\
\hline \multicolumn{5}{|l|}{ Characteristics of patients } \\
\hline Age (mean, years) & 62.79 & & $-12.40-1.73$ & 0.137 \\
\hline Sex (Female) & $7 / 36$ & 1.14 & $0.38-3.45$ & $>0.999$ \\
\hline \multicolumn{5}{|l|}{ Indication of EP } \\
\hline Abdominal pain or distension & $5 / 25$ & 1.17 & $0.38-3.67$ & $>0.999$ \\
\hline Jaundice & $2 / 8$ & 1.56 & $0.29-7.66$ & 0.635 \\
\hline Cholangitis & $0 / 6$ & 0.00 & $0.00-2.39$ & 0.586 \\
\hline Pancreatitis & $0 / 5$ & 0.00 & $0.00-3.20$ & 0.577 \\
\hline Fever and fatigue & $2 / 2$ & Infinity & 2.14 - Infinity & $0.032^{*}$ \\
\hline Incidental finding & $5 / 30$ & 0.82 & $0.27-2.91$ & $>0.999$ \\
\hline \multicolumn{5}{|l|}{ Characteristics of disease } \\
\hline Tumor size (mean, $\mathrm{cm}^{2}$ ) & 5.271 & & $-5.08-2.87$ & 0.578 \\
\hline Bile duct dilatation & $3 / 12$ & 1.84 & $0.47-8.29$ & 0.415 \\
\hline Pancreatic duct dilatation & $2 / 7$ & 1.90 & $0.34-11.14$ & 0.606 \\
\hline \multicolumn{5}{|l|}{ Pathologic type } \\
\hline Non-IN & $4 / 35$ & 0.40 & $0.13-1.45$ & 0.235 \\
\hline LIN & $0 / 11$ & 0.00 & $0.00-1.33$ & 0.199 \\
\hline $\mathrm{HIN}$ & $10 / 28$ & 6.11 & $1.62-19.01$ & $0.005 * *$ \\
\hline NT & $0 / 2$ & 0.00 & $0.00-9.71$ & $>0.999$ \\
\hline \multicolumn{5}{|l|}{ Interventions } \\
\hline Submucosal injection & $1 / 13$ & 0.32 & $0.03-2.29$ & $0.44 I$ \\
\hline \multicolumn{5}{|l|}{ Type of resection } \\
\hline En bloc & $|2 / 6|$ & 1.59 & $0.35-7.82$ & 0.723 \\
\hline Piecemeal & & & & \\
\hline \multicolumn{5}{|l|}{ Hemostasis } \\
\hline Metal clips & $12 / 63$ & 1.29 & $0.27-6.45$ & $>0.999$ \\
\hline Hemostatic sealant & $1 / 22$ & 0.15 & $0.01-0.96$ & $0.050^{*}$ \\
\hline Epinephrine & $4 / 17$ & 1.51 & $0.46-5.07$ & 0.502 \\
\hline \multicolumn{5}{|l|}{ Stent implantation } \\
\hline Pancreatic stent & $6 / 30$ & 1.19 & $0.34-3.47$ & 0.772 \\
\hline Biliary stent & $0 / 23$ & 0.00 & $0.00-0.44$ & $0.007 * *$ \\
\hline Double stent & $6 / 15$ & 3.48 & $0.98-11.72$ & $0.07 I$ \\
\hline Non stent & $2 / 8$ & 1.56 & $0.29-7.66$ & 0.635 \\
\hline Pancreatography & $10 / 39$ & 2.85 & $0.79-8.83$ & 0.139 \\
\hline
\end{tabular}

Notes: $* P \leq 0.05, * * P \leq 0.01$.

Abbreviations: non-IN, non-intraepithelial neoplasia; HIN, high-grade intraepithelial neoplasia; LIN, low-grade intraepithelial neoplasia; NT, neuroendocrine tumor; OR, odds ratio; $\mathrm{Cl}$, confidence interval.

0.15 (95\% CI, 0.01-0.96; $P=0.05)$, respectively. HIN tumors were also found directly proportional to the risk of post-EP bleeding $(\mathrm{OR}=6.11 ; 95 \% \mathrm{CI}, 1.62-19.01 ; P=0.005)$ (Table 5).

\section{Multivariate Analysis of Risk Factors for Post-EP Complications}

We also performed a multivariate analysis of the three risk factors identified in univariate analysis, including tumor 
pathologic types, hemostatic sealant application, and stent placement. Given that hemostatic sealant application was not significantly related to post-EP pancreatitis in univariate analysis and the small number of patients showing post-EP pancreatitis $(n=19)$, hemostatic sealant application was not included in the multivariate analysis of pancreatitis. Notably, tumor pathologic types and stent placement were found to be both independently associated with post-EP complications. Pathologic type of HIN was directly proportional to the likelihood of developing postEP pancreatitis, bleeding, and overall complications with ORs of 11.66 (95\% CI, 2.91-62.5; $P=0.001), 6.52$ (95\% CI, 1.45-46.77; $P=0.027)$, and 9.81 (95\% CI, 2.75-44.04; $P=0.001)$, respectively. Pancreatic stent placement was positively related to the occurrence of post-EP pancreatitis with an OR of 7.61 (95\% CI, 1.37-64.53; $P=0.033)$, but biliary stent placement was found negatively related to the occurrence of post-EP bleeding and overall complications with ORs of $0.02(95 \% \mathrm{CI}, 0-0.37 ; P=0.016)$ and 0.11 (95\% CI, 0.01-0.99; $P=0.05$ ), respectively. Interestingly, although identified as a potential post-EP bleeding-related factor in the univariate analysis, hemostatic sealant application did not show any significant association with any post-EP complication in the multivariate analysis (Table 6).

\section{Discussion}

EP has been widely used in papillary lesion treatment as a relatively safe and reliable procedure. Nevertheless, post-EP complications have significant impacts on the prognosis and recovery in some patients, which may restrict EP's broader application. Systematic evaluation of EP safety and associated risk factors could help to decrease the incidence and severity of post-EP complications. In this study, we conducted a single-center retrospective study of post-EP complications and their related risk factors among a total of 76 patients. Our study has several novelties and new findings compared with previous EP-related studies. First, our study adopted a grading system for the first time to evaluate EP's overall safety in papillary lesions treatment. Different from the relatively high rates of post-EP complications reported in the previous studies $(\sim 35 \%),{ }^{6,14,20,22}$ our analysis showed instead that most $(60.7 \%)$ of the complications were mild, supporting the notion that EP is an overall safe procedure

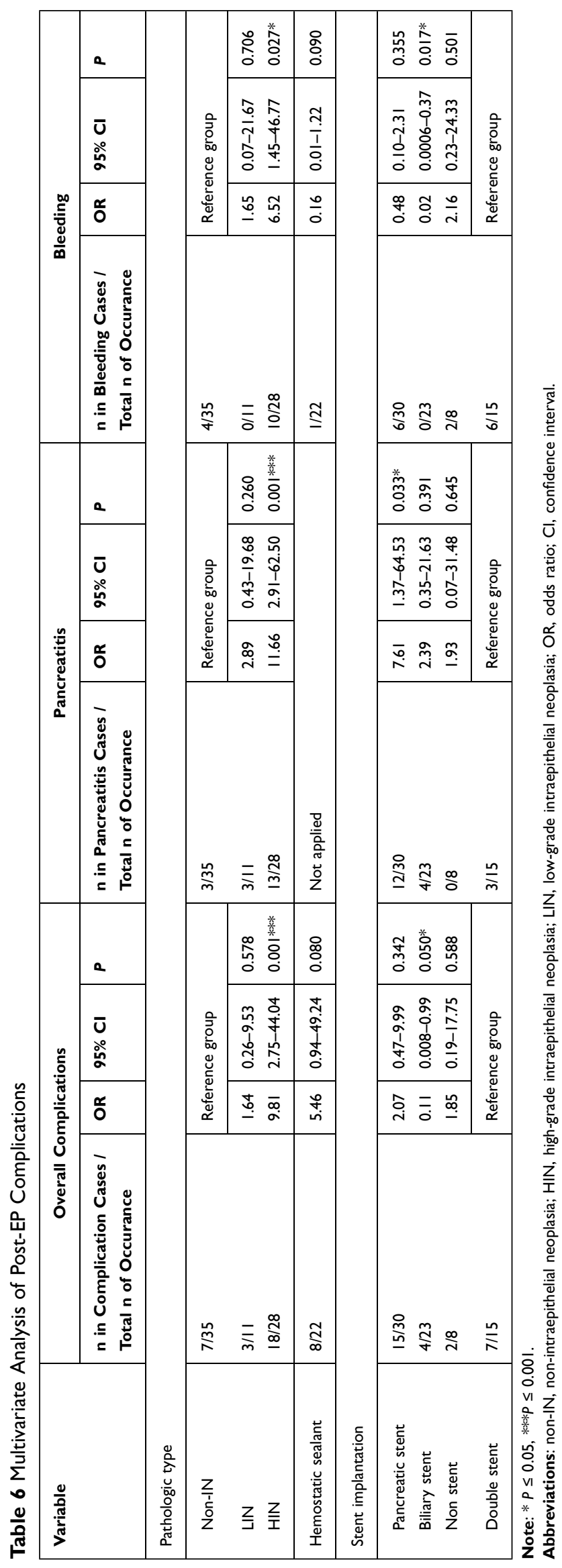


in papillary lesion treatment. Second, previous studies only adopted a univariate analysis of risk factors for EP complications. In contrast, our study applied both univariate and multivariate analyses and evaluated a higher number of potential risk factors. This led to the identification of two outstanding risk factors, including pathologic tumor types and stent placement. In particular, biliary stenting is first found to reduce the occurrence of post-EP bleeding and overall complications.

Previous EP-related studies had reported various incidences of postoperative complications, ranging from $8 \%$ to $35 \%$, and the mortality rate was about $0.4 \%$ in some studies. $^{7,14,16,18,26,27}$ In our EP patients, the incidence of post-EP complications was $36.8 \%$, similar to the previous studies. It is worth mentioning that previous studies did not evaluate the severity of post-EP complications. Our study showed that most complications (60.7\%) in EP patients were mild, while only $21.4 \%$ of cases were moderate and $17.9 \%$ were severe. These three grades accounted for $22.4 \%, 7.9 \%$, and $6.7 \%$ of all our EP patients, respectively. Moreover, all the post-EP complications were improved after prompt treatment, and no EPrelated death was reported in our patients. Altogether, our study supports the overall safety of EP procedure in papillary lesion treatment.

Identifying significant risk factors can help to select patients eligible for EP operation and choose the best procedures to reduce the incidence and severity of postEP complications. Previous studies had primarily focused on risk factors related to post-EP pancreatitis with only univariate analysis, and many of their results and conclusions are inconsistent or even conflicting. For example, one study indicated that larger tumors and pancreatic duct dilution were associated with a lower risk of postoperative pancreatitis; ${ }^{21}$ however, another study reported that small tumor size and absence of pancreaticobiliary duct dilatation were related to successful surgery. ${ }^{10}$ Thus, a more comprehensive analysis of risk factors for more post-EP complications is needed.

Our study assessed five common post-EP complications and examined twelve potential risk factors utilizing both univariate and multivariate analyses. Notably, two risk factors, including pathologic types and stent placement, are significantly associated in both analyses $(P<0.05)$. Interestingly, when we applied $P<0.005$ as the significance threshold, only pathologic types but not stent placement exhibited significant association with post-EP complications. This indicates a stronger correlation between pathologic types and post-EP complications. In particular, we found that the lesion with HIN was positively related to the post-EP complications, while the non-IN lesion showed a negative correlation. Thus, EP is better recommended for patients with non-IN lesions, while the application of EP in patients with HIN lesions or more malignant tumors should be cautious for the postoperative complications.

Stent placement showed a less strong significance with $P$-value between 0.05 and 0.005 . In our analysis, four different types of stent placements were analyzed, including pancreatic stenting, biliary stenting, no stenting, and double stenting. Among them, pancreatic stenting was found to potentially contribute to the occurrence of post-EP pancreatitis, while biliary stenting seemed to prevent overall complications. Why do these two types of stents produce opposite effects? Pancreatic stenting is generally considered to be more challenging than biliary stenting. There is a higher risk of injury and contamination during the pancreatic duct cannulation and stent placement. By contrast, the biliary duct is easier to cannulate, and therefore the placement is less likely to introduce injury. In addition, biliary stenting could benefit patients by helping bile drainage and preventing bile reflux-induced pancreatitis and bile-induced wound bleeding. Therefore, we suggest that pancreatic stenting, especially for patients with difficulty to cannulate pancreatic ducts, is unnecessary unless it is required due to other concerns. On the other hand, biliary stenting could be considered a preventative method for overall post-EP complications.

It is worth mentioning that previous studies showed conflicting conclusions on the effects of pancreatic stenting on postoperative pancreatitis. ${ }^{8,18,19,28}$ Some studies claim that pancreatic stents placement could reduce pancreatitis incidence by preventing stenosis of the pancreatic duct and helping the drainage of pancreatic fluid. ${ }^{9,18,23,28}$ However, other studies suggest pancreatic stenting is not effective in preventing postoperative pancreatitis and even increases the risk due to the repeated pancreatic duct cannulation. $^{8,19,21,29}$ In our study, we also found pancreatic stenting increased the occurrence of post-EP pancreatitis. Therefore, further study with increased sample size and multi-center study is required in the future.

Studies of biliary stenting on post-EP complications are still largely missing, and only a few studies have suggested the notion that biliary stenting can reduce postoperative cholangitis, but the effect on other complications has not yet been revealed. ${ }^{22,29,30}$ Our study demonstrates 
for the first time that biliary stenting alone in EP is effective in reducing the incidence of postoperative bleeding and overall complications.

Submucosal injection was performed on $17.1 \%$ of our patients when the endoscopist thought it was necessary considering the specific lesion features or other conditions. Consistent with previous studies, our study did neither find any significant effect of submucosal injection on post-EP complications. $^{20,31,32}$ Therefore, we do not recommend it as a standard step for EP procedure.

As a retrospective study, this study had some limitations. First, it is a single-center study, therefore difficult to generalize the results of this study to other different environments. Second, the sample size was relatively small, and only 76 patients were involved in this study. Third, some other risk factors of post-EP complications were not included, such as preoperative application of NSAIDs. Therefore, a multicenter, large-sample study is needed for further research.

\section{Conclusion}

In conclusion, EP is a relatively safe procedure in papillary lesion treatment with low rates of complications and mortality, and most post-EP complications are mild. Both univariate and multivariate analyses in this study revealed that the pathologic tumor types and stent placement are risk factors of post-EP complications. More prospective studies with a large sample size would help to uncover other risk factors related to complications and provide further guidance for clinical practice.

\section{Ethics Statement}

This study was conducted in accordance with the Declaration of Helsinki. The requirement for ethical approval was waived according to the Ethics Committee of Chinese PLA General Hospital due to the retrospective nature of the study. Written informed consent was obtained from each participant of this study.

\section{Acknowledgments}

We thank Dr. Wen Li, Dr. Fengchun Cai, Dr. Xu Guo, Jiangyun Meng, Xiangdong Wang, Ping Tang, Jing Zhu, Hong Du, and Hongbin Wang for their help and support. We also thank Julia Jones for English language editing.

\section{Author Contributions}

All authors contributed to data analysis, drafting or revising the article, have agreed on the journal to which the article will be submitted, gave final approval of the version to be published, and agree to be accountable for all aspects of the work.

\section{Funding}

This study was supported by the National Key R and D Program of China (No.2016YFC1303601).

\section{Disclosure}

The authors report no conflicts of interest in this work.

\section{References}

1. Bohnacker S, Soehendra N, Maguchi H, Chung JB, Howell DA. Endoscopic resection of benign tumors of the papilla of vater. Endoscopy. 2006;38(5):521-525. doi:10.1055/s-2006-925263

2. Stolte M, Pscherer C. Adenoma-carcinoma sequence in the papilla of Vater. Scand J Gastroenterol. 1996;31(4):376-382. doi:10.3109/ 00365529609006414

3. Kim MH, Lee SK, Seo DW, Won SY, Lee SS, Min YI. Tumors of the major duodenal papilla. Gastrointest Endosc. 2001;54(5):609-620. doi:10.1067/mge.2001.119254

4. Silvis SE. Endoscopic snare papillectomy. Gastrointest Endosc. 1993;39(2):205-207. doi:10.1016/S0016-5107(93)70074-7

5. Adler DG, Qureshi W, Davila R, et al.; Standards of Practice C. The role of endoscopy in ampullary and duodenal adenomas. Gastrointest Endosc. 2006;64(6):849-854. doi:10.1016/j.gie.2006.08.044.

6. Napoleon B, Gincul R, Ponchon T, et al. Endoscopic papillectomy for early ampullary tumors: long-term results from a large multicenter prospective study. Endoscopy. 2014;46(2):127-134. doi:10.1055/ s-0034-1364875

7. Attila T, Parlak E, Alper E, Disibeyaz S, Cicek B, Odemis B. Endoscopic papillectomy of benign ampullary lesions: outcomes from a multicenter study. Turk $J$ Gastroenterol. 2018;29 (3):325-334. doi:10.5152/tjg.2018.17378

8. Norton ID, Gostout CJ, Baron TH, Geller A, Petersen BT, Wiersema MJ. Safety and outcome of endoscopic snare excision of the major duodenal papilla. Gastrointest Endosc. 2002;56 (2):239-243. doi:10.1016/S0016-5107(02)70184-3

9. Catalano MF, Linder JD, Chak A, et al. Endoscopic management of adenoma of the major duodenal papilla. Gastrointest Endosc. 2004;59(2):225-232. doi:10.1016/S0016-5107(03)02366-6

10. Irani S, Arai A, Ayub K, et al. Papillectomy for ampullary neoplasm: results of a single referral center over a 10-year period. Gastrointest Endosc. 2009;70(5):923-932. doi:10.1016/j.gie.2009.04.015

11. Jung MK, Cho CM, Park SY, et al. Endoscopic resection of ampullary neoplasms: a single-center experience. Surg Endosc. 2009;23 (11):2568-2574. doi:10.1007/s00464-009-0464-9

12. Igarashi Y, Okano N, Ito K, Mimura T, Nakano S. Endoscopic snare excision of a major duodenal papillary tumor. Dig Surg. 2010;27 (2):119-122. doi: $10.1159 / 000286715$

13. Will U, Muller AK, Fueldner F, Wanzar I, Meyer F. Endoscopic papillectomy: data of a prospective observational study. World J Gastroenterol. 2013;19(27):4316-4324. doi:10.3748/wjg.v19.i27.4316

14. Tsuji S, Itoi T, Sofuni A, Mukai S, Tonozuka R, Moriyasu F. Tips and tricks in endoscopic papillectomy of ampullary tumors: single-center experience with large case series (with videos). $J$ Hepatobiliary Pancreat Sci. 2015;22(6):E22-27. doi:10.1002/jhbp.207

15. Katsinelos P, Paroutoglou G, Kountouras J, et al. Safety and long-term follow-up of endoscopic snare excision of ampullary adenomas. Surg Endosc. 2006;20(4):608-613. doi:10.1007/s00464004-2278-0 
16. Lee R, Huelsen A, Gupta S, Hourigan LF. Endoscopic ampullectomy for non-invasive ampullary lesions: a single-center 10-year retrospective cohort study. Surg Endosc. 2020;35(2):684-692. doi:10.1007/ s00464-020-07433-7

17. Minami K, Iwasaki E, Kawasaki S, et al. A long $(7 \mathrm{~cm})$ prophylactic pancreatic stent decreases incidence of post-endoscopic papillectomy pancreatitis: a retrospective study. Endosc Int Open. 2019;7(12): E1663-E1670. doi:10.1055/a-1010-5581

18. Ismail S, Marianne U, Heikki J, Jorma H, Leena K. Endoscopic papillectomy, single-centre experience. Surg Endosc. 2014;28 (11):3234-3239. doi:10.1007/s00464-014-3596-5

19. Chang WI, Min YW, Yun HS, et al. Prophylactic pancreatic stent placement for endoscopic duodenal ampullectomy: a single-center retrospective study. Gut Liver. 2014;8(3):306-312. doi:10.5009/ gnl.2014.8.3.306

20. Kang SH, Kim KH, Kim TN, et al. Therapeutic outcomes of endoscopic papillectomy for ampullary neoplasms: retrospective analysis of a multicenter study. BMC Gastroenterol. 2017;17(1):69. doi:10.1186/s12876-017-0626-5

21. Taglieri E, Micelli-Neto O, Bonin EA, et al. Analysis of risk factors associated with acute pancreatitis after endoscopic papillectomy. $\mathrm{Sci}$ Rep. 2020;10(1):4132. doi:10.1038/s41598-020-60941-3

22. Ito K, Fujita N, Noda Y, et al. Impact of technical modification of endoscopic papillectomy for ampullary neoplasm on the occurrence of complications. Dig Endosc. 2012;24(1):30-35. doi:10.1111/j.14431661.2011.01161.x

23. Harewood GC, Pochron NL, Gostout CJ. Prospective, randomized, controlled trial of prophylactic pancreatic stent placement for endoscopic snare excision of the duodenal ampulla. Gastrointest Endosc. 2005;62(3):367-370. doi:10.1016/j.gie.2005.04.020

24. Yamao T, Isomoto H, Kohno S, et al. Endoscopic snare papillectomy with biliary and pancreatic stent placement for tumors of the major duodenal papilla. Surg Endosc. 2010;24(1):119-124. doi:10.1007/ s00464-009-0538-8
25. Cotton PB, Lehman G, Vennes J, et al. Endoscopic sphincterotomy complications and their management: an attempt at consensus. Gastrointest Endosc. 1991;37(3):383-393. doi:10.1016/S00165107(91)70740-2

26. Soma H, Miyata N, Hozawa S, et al. Ampullary adenoma treated by endoscopic double-snare retracting papillectomy. Gut Liver. 2015;9 (5):689-692. doi:10.5009/gnl14206

27. Sahar N, Krishnamoorthi R, Kozarek RA, et al. Long-term outcomes of endoscopic papillectomy for ampullary adenomas. Dig Dis Sci. 2020;65(1):260-268. doi:10.1007/s10620-019-05812-2

28. Napoleon B, Alvarez-Sanchez MV, Leclercq P, et al. Systematic pancreatic stenting after endoscopic snare papillectomy may reduce the risk of postinterventional pancreatitis. Surg Endosc. 2013;27 (9):3377-3387. doi:10.1007/s00464-013-2920-9

29. Attaallah W, Gunal O, Mokhtare S, Ozmen T, Cingi A. Endoscopic snare excision of adenoma of the papilla of Vater without prophylactic pancreatic-duct stent.. JOP. 2014;15(6):587-590. doi:10.6092/ $1590-8577 / 2639$

30. Ghidirim G, Misin I, Istrate V, Cazacu S. Endoscopic papillectomy into the treatment of neoplastic lesions of vater papilla. Curr Health Sci J. 2009;35(2):92-97.

31. Chung KH, Lee SH, Choi JH, et al. Effect of submucosal injection in endoscopic papillectomy of ampullary tumor: propensity-score matching analysis. United European Gastroenterol J. 2018;6 (4):576-585. doi:10.1177/2050640617745459

32. Hyun JJ, Lee TH, Park JS, et al. A prospective multicenter study of submucosal injection to improve endoscopic snare papillectomy for ampullary adenoma. Gastrointest Endosc. 2017;85(4):746-755. doi:10.1016/j.gie.2016.08.013
Therapeutics and Clinical Risk Management

\section{Publish your work in this journal}

Therapeutics and Clinical Risk Management is an international, peerreviewed journal of clinical therapeutics and risk management, focusing on concise rapid reporting of clinical studies in all therapeutic areas, outcomes, safety, and programs for the effective, safe, and sustained use of medicines. This journal is indexed on PubMed Central, CAS,

\section{Dovepress}

EMBase, Scopus and the Elsevier Bibliographic databases. The manuscript management system is completely online and includes a very quick and fair peer-review system, which is all easy to use. Visit http://www.dovepress.com/testimonials.php to read real quotes from published authors. 